\title{
Editorial: A "teoria do processo penal" e as suas relações entre continentes
}

\author{
Editorial: The "theory of criminal procedure" \\ and its relations between continents
}

\author{
Bruna Capparelli \\ Doutora em Processo Penal pela Università di Bologna (Itália). \\ Doutora em Ciências Criminais pela PUCRS (em regime de cotutela). \\ Bacharel em Direito pela Università di Bologna (Itália). \\ Associate editor da RBDPP. \\ bruna.capparelli2@unibo.it \\ http://orcid.org/0000-0003-1249-2658
}

Nereu José Giacomolli

Doutor em Direito Processual Penal pela Universidad Complutense de Madri (Espanha). Coordenador de Pesquisa - PUCRS. Professor titular de Direito Processual Penal - PUCRS. Editor chefe da RBDPP. nereu@giacomolli.com lattes.cnpq.br/5969235847033808 http://orcid.org/0000-0003-1753-0334

Resumo: Neste editorial os autores expõem as premissas dos pontos de consolidação para uma "teoria do processo penal" e das suas relações entre os estudiosos italianos e latinos, assentando algumas orientações que guiam a RBDPP.

Palavras-chave: Processo Penal italiano; Processo Penal na América Latina; Pontos de intersecção; RBDPP.

ABSTRACT: In this editorial, the Authors expose the premises of consolidation points for a "theory of the criminal procedure" and its relations between Italian and Latin academics, laying down some guidelines that guide RBDPP.

KEYwords: Italian Criminal Procedure; Criminal Procedure in Latin America; Points of intersection; RBDPP. 
A pesquisa, os pesquisadores, a justiça penal. Em tempos como os nossos de extrema dificuldade para os destinos da Universidade, nos locais dedicados à comunicação se discute muito sobre as atuais quantificações mercantis do produto "pesquisa" e acerca das abstratas classificações em estratos e em medianas das publicações, em busca de respostas imediatas a problemas bem mais profundos e complexos.

Outro fator de interesse para nossos fins é o aumento da tendência à “superespecialização", pela qual, como é notório, com sempre maior frequência surgem novos periódicos que circunscrevem o argumento dos trabalhos publicados em setores cada vez mais restritos. Uma segregação especialística que torna mais difícil a pesquisa interdisciplinar nos espaços de sobreposições entre diferentes disciplinas, as quais, todavia, são certamente reconhecidas como as mais férteis pelos pesquisadores dotados de maior criatividade e capacidade de síntese.

Ademias, hoje acredita-se - ou pensa-se que seja indispensável sustentar - que a força de uma matéria consista em rígidas separações científicas. Esta bandeira merece respeito e sem dúvidas ainda possui relevância. Todavia, uma disciplina não pode conter tudo aquilo que conta, porque o postulado da autonomia não é útil sem sua totalidade. $\mathrm{O}$ processo penal perpassa o terreno de várias outras áreas do conhecimento e saber, e, para compreendê-lo a fundo, como se atua, a sua indigência e suas virtudes, não é possível ignorar as críticas das áreas limítrofes.

Neste complexo quadro delineado se insere a RBDPP: embora permanecemos persuadidos de que o diálogo interdisciplinar constitua uma base elementar, quase escolástica para o processo penal hodierno, e conscientes de que um modelo de jurista superespecializado possa parecer para alguns pouco atraente, assim de como seja ainda forte o sentimento nostálgico no que tange à figura de um estudioso que invocava a "teoria geral única de processo" para a resolução de intrigantes questões jurídicas relativas as incitações impostas pela justiça penal, a RBDPP lança um desafio.

Apesar de considerar legítimas as nostalgias do passado, como aquelas que cada um de nós nutre em seu íntimo, por exemplo, pela romântica figura do "médico de família" - capaz de solucionar, imediatamente, qualquer problema-, se pretendemos permanecer aos passos com os tempos e tentar melhorar a função pública cuja pesquisa e didática são 
predispostos, seria mais conveniente apartar essas nostalgias. Podemos não aprovar o norte seguido pelo mundo, mas não podemos pretender que ele paralise para que possamos descer. Em vez disso, seria muito mais produtivo tentar compreender o movimento e ficarmos bem ancorados às próprias referências, para que não sejamos ejetados.

Entendendo a exploração desta forma, temos então boas razões para sustentar a ideia de um Direito Processual Penal que se autodetermine por categorias próprias, que avance, que se afirme com (e por) público consenso dos estudiosos. Esta é uma visão que seduz verdadeiramente, e está, ainda, em busca de prosélitos. Mas - pelo menos nos nossos dias - a experiência desilude. Por trás daquelas nostalgias citadas acima se escondem não somente riscos e perigos, mas realidades diversas, às vezes malignas: conclusões exibidas por quem não conhece a fundo, ocasiões para estocadas científicas anteriores a qualquer aprofundamento, "bandeiras balançadas" que fragilizam o Direito Processual Penal e que não raramente interferem, quando o percurso está ainda em fase de formação.

Com seu projeto editorial, a RBDPP reverbera uma advertência, partindo do desengano em relação à reivindicação "coral" de uma visão do Processo Penal meramente instrumental.

Relativamente a dita instrumentalidade do Direito Processual sobre o Direito Penal substancial, evidenciá-la é útil ao fim de afirmar uma função que se pode definir fisiologicamente própria do processo penal: de fato, o processo seria somente um dispositivo continuamente imóvel, privado de voz se não fosse destinado a dar concreta aplicação às regras sobre delitos e penas. Ao contrário, é indispensável precisar que o Direito Penal material adquire concreta aplicação e atuação não somente quando se aplica uma sanção penal, abstratamente imposta, a um ou mais sujeitos contra um ou mais crimes legalmente investigados, mas também quando em face a acertamentos de fato, ou de interpretações de normas, emerge que, em relação a um determinado fato, não deve incidir alguma sanção contra o réu, no que diz respeito ao fato contestado.

Entretanto, como é notório, a estrutura do vigente Código de Processo Penal descreve percursos idôneos a confluir em atos processuais aplicativos de sanções qualificáveis como penal ou, em alternativa, certificados pela não aplicação de tais sanções, antepondo-se regras mirantes a delinear um quadro normativo de sujeitos e atos destinados 
a comparecer na cena de todo o iter procedimental e oferecer uma disciplina de institutos cuja relevância é largamente transversal (id est: o tema das provas e das medidas cautelares, os vários aspectos da execução de medidas durante ou ao fim do processo, a formação do trânsito em julgado e de seus efeitos penais ou extrapenais, as relações jurisdicionais com autoridades estrangeiras). O resultado é um catálogo de matérias que dificilmente seria possível imaginar como estranhas ao denominado Direito Processual Penal, visto que de cada uma delas se descreve uma disciplina, em suas diferentes etapas e variações, chegando a compor um verdadeiro "procedimento" penal.

Que na Itália o Direito Processual Penal tenha adquirido, ao longo do tempo, uma autonomia própria quanto à categoria conceitual e institutos jurídicos, é um dado incontroverso ${ }^{1}$. Ademais, a estes propósitos, é suficiente repercorrer a evolução dos programas acadêmicos italianos que levaram em 1938 a instituir o ensinamento autônomo do Processo Penal, visto que, até aquele ano, o Direito Processual era parte integrante dos cursos de Direito Penal ${ }^{2}$.

Justamente a partir de 1938 a cadeira de Processo Penal se transforma em um curso próprio, embora continue sendo atribuído, em custódia, aos docentes de Direito Penal substancial ${ }^{3}$.

Como se recordará, a partir da segunda metade dos anos 50, as universidades italianas iniciam a recrutar docentes que se dedicarão, de modo exclusivo, ao ensino do Direito Processual Penal.

1 Cfr. CONSO, Giovanni. Istituzioni di diritto processuale penale, Milano: Giuffrè, $2^{\circ}$ ed., 1967.

2 Por todos: ORLANDI, Renzo. Il metodo della ricerca nelle scienze penalistiche. Uno sguardo alle discipline processuali. In: Scritti in onore di Luigi Stortoni, Bologna: Bononia University Press, 2016, p. 99 - 114 e ORLANDI, Renzo. La prolusione di Rocco e le dottrine del processo penale. Criminalia, 2010, p. 2 s.

3 Neste sentido, uma decisiva contribuição se individualiza na cisão operada em 1938 na tabela dos cursos curriculares para a obtenção da licenciatura em Direito, entre o Direito Penal e Procedimento Penal, antes disciplinados conjuntamente com a denominação "Direito e Processo Penal". Hoje, o Direito Processual Penal, distinto do Direito Penal, marca um dos específicos setores científicos individualizados dentro da grande área de Ciências Jurídicas pelo decreto ministerial de 23 de dezembro de 1999 designando também uma das «atividades formativas indispensáveis» para a obtenção da «licenciatura em Direito», segundo a definição dada pelo D.M. de 25 de novembro de 2005. 
Contudo, se para a cultura jurídica italiana hodierna a alteridade do Direito Penal substancial e do Direito Processual Penal pode se dizer aceita, em um contexto que consagrou até mesmo em nível acadêmico, uma dignidade científica e didática entre as duas disciplinas, formalmente separadas, o mesmo não pode se dizer acerca do ensino da matéria e das atividades de pesquisa no ordenamento brasileiro, onde ainda prevalece um certo prejuízo em relação ao reconhecimento de um Direito Processual Penal tecnicamente rigoroso, e, sobretudo, autônomo ${ }^{4}$.

De fato, a uma análise mais atenta, é possível individuar uma espécie de semi-encobrimento do Processo Penal enquanto tal, reconduzido, na maior parte das vezes, a um apêndice do Penal substancial, sobreposto a uma organização e atuação prática dos ensinamentos universitários (basta examinarmos o número de horas/aula dedicadas ao ensino do direito material e a correspondência didática de direito processual penal).

Por outro lado, são diversos os ilustres doutrinadores processuais penalistas italianos cuja fama ultrapassou desde muito tempo o atlântico, influenciando determinantemente inteiras gerações de estudiosos em toda a América Latina ${ }^{5}$ além dos grandes clássicos como Francesco Carrara $^{6}$ - somente para citar um exemplo -, em uma fase mas recente encontramos mestres do calibro de Giovanni Conso $^{7}$, Franco Cordero ${ }^{8}$,

4 Na mesma direção: CHIAVARIO, Mario. (Voz) Diritto processuale penale. Enciclopedia del Diritto, 2016, Milano: Giuffrè, p. $255 \mathrm{~s}$.

5 V., entre muitos, PELLEGRINI GRINOVER, Ada. Lineamenti generali del nuovo processo penale dell'America Latina: Argentina, Brasile e Codice modello per l'America Latina. Giusto proc., 1990, 32 s.; PELLEGRINI GRINOVER, Ada. Lineamenti generali del nuovo processo penale in America Latina e punti di convergenza con il modello italiano. In CHIAVARIO, Mario. (a cura di). Il nuovo codice di procedura penale visto dall'estero (Atti del seminario di Torino, 4-5 maggio 1990), Milano: Giuffrè, 1991, 137 s. e ARMIENTA CALDERÓN, Gonzalo. La nueva reforma procesal penal mexicana. In MASSA, M.; SCHIPANI, S. (a cura di). Un "Codice Tipo" di Procedura Penale per l'America Latina (Atti del Convegno Internazionale, Roma 11/13 settembre 1991), (Roma e America. Collana di studi giuridici latino-americani, 7), Padova: Cedam, 1994, 315 s.

6 CARRARA, Francesco. Programma del corso di diritto criminale, 1863.

7 CONSO, Giovanni. I fatti giuridici processuali penali: perfezione ed efficacia, 1955.

8 CORDERO, Franco. Le situazioni soggettive nel processo penale, Torino, 1956. 
Luigi Ferrajoli ${ }^{9}$, Massimo Nobili ${ }^{10}$, Paolo Ferrua ${ }^{11}$, Vittorio Grevi ${ }^{12}$, Ennio Amodio $^{13}$, Mario Chiavario, Giulio Illuminati ${ }^{14}$.

O nosso desafio, portanto, é criar uma ocasião de dialogo, de interação, de manter vivas as interseções desta florida e tradicional parceria entre o Processo Penal italiano e o Processo Penal na América Latina, de abrir um novo canal através dos nossos Autores e Revisores, embora que com seleção e com os mascaramentos que impõem a deontologia.

O resultado é algo que não coincide com os gêneros editoriais mais comuns, permanecendo teimosa a opinião que o fio destinado a ligar as partes mais heterogêneas da Revista não estejam somente em predileções pessoais.

\section{Bibliografia}

AMODIO, Ennio. Estetica della giustizia penale, Milano: Giuffrè, 2016.

AMODIO, Ennio. Motivazione della sentenza penale, in Enc. dir., vol. XXVII, Milano, 1977, p.173 s.

ARMIENTA CALDERÓN, Gonzalo. La nueva reforma procesal penal mexicana. In MASSA, M.; SCHIPANI, S. (a cura di). Un "Codice Tipo" di Procedura Penale per l'America Latina (Atti del Convegno Internazionale, Roma 11/13 settembre 1991), (Roma e America. Collana di studi giuridici latino-americani, 7), Padova: Cedam,1994, $315 \mathrm{~s}$.

9 FERRAJOLI, Luigi. Diritto e ragione. Teoria del garantismo penale, Laterza, 2009.

10 NOBILI, Massimo. La disciplina costituzionale del processo: appunti di procedura penale dal corso del Prof. Massimo Nobili, 1976 e NOBILI, Massimo. Il principio del libero convincimento del giudice, Milano,1974.

11 FERRUA, Paolo. Il "giusto processo", Bologna: Zanichelli, 2012 e FERRUA, Paolo. Oralità del giudizio e letture di deposizioni testimoniali, Milano,1981.

12 GREVI, Vittorio. Nemo tenetur se detegere: interrogatorio dell'imputato e diritto al silenzio nel processo penale italiano, Milano, 1972.

13 AMODIO, Ennio. Motivazione della sentenza penale, in Enc. dir., vol. XXVII, Milano 1977, p.173 s. e, mais de recente, AMODIO, Ennio. Estetica della giustizia penale, Milano: Giuffrè, 2016.

${ }^{14}$ ILLUMINATI, Giulio. La presunzione d'innocenza dell'imputato, Bologna, 1979. 
CARRARA, Francesco. Programma del corso di diritto criminale, 1863.

CHIAVARIO, Mario. Processo e garanzie della persona, Milano, 1976.

CHIAVARIO, Mario. (Voz) Diritto processuale penale. Enciclopedia del Diritto, 2016, Milano: Giuffrè, p. 255 s.

CONSO, Giovanni. I fatti giuridici processuali penali: perfezione ed efficacia, 1955.

CONSO, Giovanni. Istituzioni di diritto processuale penale, Milano: Giuffrè, $2^{\circ}$ ed., 1967.

CORDERO, Franco. Le situazioni soggettive nel processo penale, Torino, 1956.

FERRAJOLI, Luigi. Diritto e ragione. Teoria del garantismo penale, Laterza, 2009.

FERRUA, Paolo. Oralità del giudizio e letture di deposizioni testimoniali, Milano, 1981.

FERRUA, Paolo. Il “giusto processo”, Bologna: Zanichelli, 2012.

GREVI, Vittorio. Nemo tenetur se detegere: interrogatorio dell'imputato e diritto al silenzio nel processo penale italiano, Milano, 1972.

ILLUMINATI, Giulio. La presunzione d'innocenza dell'imputato, Bologna, 1979.

NOBILI, Massimo. Il principio del libero convincimento del giudice, Milano,1974.

NOBILI, Massimo. La disciplina costituzionale del processo: appunti di procedura penale dal corso del Prof. Massimo Nobili, 1976.

ORLANDI, Renzo. Il metodo della ricerca nelle scienze penalistiche. Uno sguardo alle discipline processuali. In: Scritti in onore di Luigi Stortoni, Bologna: Bononia University Press, 2016, p. 99 - 114.

ORLANDI, Renzo. La prolusione di Rocco e le dottrine del processo penale. Criminalia, 2010, p. 2 s.

PELLEGRINI GRINOVER, Ada. Lineamenti generali del nuovo processo penale dell'America Latina: Argentina, Brasile e Codice modello per l'America Latina. Giusto proc., 1990, 32 s.

PELLEGRINI GRINOVER, Ada. Lineamenti generali del nuovo processo penale in America Latina e punti di convergenza con il modello italiano. In CHIAVARIO, Mario (a cura di). Il nuovo codice di procedura penale visto dall'estero (Atti del seminario di Torino, 4-5 maggio 1990), Milano: Giuffrè, 1991, 137 s. 


\section{Informações adicionais e declarações dos autores (integridade científica)}

Agradecimentos: os autores agradecem o prof. Vinicius Gomes de Vasconcellos pela atenta e valiosa revisão do editorial.

Declaração de conflito de interesses (conflict of interest declaration): os autores confirmam que não há conflitos de interesse na realização das pesquisas expostas e na redação deste editorial.

Declaração de autoria (declaration of authorship): todas e somente as pessoas que atendem os requisitos de autoria deste editorial estão listadas como autores; todos os coautores se responsabilizam integralmente por este trabalho em sua totalidade.

- Bruna Capparelli: projeto e esboço inicial, levantamento bibliográfico, revisão bibliográfica, redação, aprovação da versão final.

- Nereu Giacomolli: revisão crítica e complementação bibliográfica, redação, aprovação da versão final.

Declaração de ineditismo e originalidade (declaration of originality): os autores asseguram que o texto aqui publicado não foi divulgado anteriormente em outro meio e que futura republicação somente se realizará com a indicação expressa da referência desta publicação original; também atestam que não há plágio de terceiros ou autoplágio.

\section{COMO CITAR ESTE EDITORIAL:}

CAPPARELLI, Bruna; GIACOMOLLI, Nereu. A "teoria do processo penal" e as suas relações entre continentes. Revista Brasileira de Direito Processual Penal, Porto Alegre, vol. 4, n. 3, p. 913-920, set./dez. 2018. https://doi.org/10.22197/rbdpp.v4i3.194

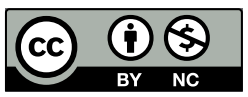

Esta obra está licenciada com uma Licença Creative Commons Atribuição-NãoComercial 4.0 Internacional. 